\title{
A new intranasal therapy (MP29-02*) is more effective than current firstline therapy regardless of season, symptom or severity.
}

\author{
Claus Bachert ${ }^{1 *}$, Wytske Fokkens ${ }^{2}$, Peter Hellings ${ }^{3}$, Glenis Scadding ${ }^{4}$, Ullrich Munzel ${ }^{5}$, Joaquim Mullol ${ }^{6}$ \\ From The 10th Symposium of Experimental Rhinology and Immunology of the Nose (SERIN 2015) \\ Stockholm, Sweden. 19-21 February 2015
}

\section{Background}

Moderate-to-severe allergic rhinitis (AR) is often poorly controlled. Patients remain symptomatic on treatment, despite multiple therapies. A more effective treatment is needed. We assessed the efficacy of MP29-02* (a novel intranasal formulation of azelastine hydrochloride (AZE) and fluticasone propionate (FP) in an advanced delivery system) during different seasons and for different symptoms and severities vs AZE, FP or placebo (PLA).

\section{Method}

Four thousand and twenty two moderate/severe SAR patients ( $\geq 12$ yrs) were randomized into 4 double-blind, PLA-controlled, 14-day, parallel-group trials to MP29-02*, AZE, FP or PLA nasal sprays (1 spray/nostril bid), during the Texas mountain cedar (MP4001), Spring (MP4002), Autumn (MP4004) and Spring/Summer (MP4006) seasons. Overall change from baseline (CFB) in reflective total nasal symptom score (rTNSS) was the primary endpoint. It was assessed by severity post-hoc in 2 ways (more severe AR: median baseline rTNSS $>18.9$ or median baseline RQLQ >3.9; less severe AR: median baseline rTNSS $\leq 18.9$ or median baseline RQLQ $\leq 3.9)$. CFB in individual nasal and ocular symptom scores was also assessed.

\section{Results}

The response to MP29-02* was consistent across seasons; mean CFB -5.5, -5.5, -5.6 and -5.6 in each study ( $<<0.001$ vs PLA). Nasal symptom relief was significantly greater with MP29-02* than with FP or AZE in all studies. In study MP4001 MP29-02 was approx. twice as effective as FP (relative difference (RD) 47\%; $\mathrm{p}=0.0031$ ) and 3 times as

${ }^{1}$ Ghent University Hospital, Dept of Oto-Rhinolaryngology, Ghent, Belgium Full list of author information is available at the end of the article effective as AZE (RD: 66\%; $\mathrm{p}<0.0001)$. For less severe AR (defined by median baseline rTNSS) the RD to MP29-02* was $42 \%$ vs FP ( $\mathrm{p}=0.0188)$ and $64 \%$ vs AZE ( $\mathrm{p}=0.0002)$, increasing to $49 \%$ and $70 \%$ vs FP ( $\mathrm{p}=0.0436)$ and AZE $(\mathrm{p}=0.0035)$, respectively for more severe AR. When severity was categorized according to median baseline RQLQ the RD to MP29-02\% was $60 \%$ vs FP ( $p=0.0244)$ and $69 \%$ vs AZE ( $\mathrm{p}=0.0068$ ) for those with less severe AR compared to $49 \%$ vs FP ( $\mathrm{p}=0.0194)$ and $64 \%$ vs AZE ( $\mathrm{p}=0.0013$ ) for those with more severe AR. MP29-02* provided superior relief from all nasal and ocular symptoms than AZE or FP, which was particularly evident for congestion $(p=0.0034$ vs FP; $p=0.0001$ vs AZE) \& ocular itching ( $\mathrm{p}=0.0240$ vs FP; $\mathrm{p}=0.0033$ vs $\mathrm{AZE})$.

\section{Conclusion}

MP29-02* provides consistently superior symptomatic relief to an intranasal antihistamine or topical corticosteroid in AR patients regardless of season, symptom or severity, supporting MP29-02 as the drug of choice for AR.

"Dymista

\section{Authors' details \\ 'Ghent University Hospital, Dept of Oto-Rhinolaryngology, Ghent, Belgium. ${ }^{2}$ Academic Medical Center, Department of Otorhinolaryngology, Amsterdam, Netherlands. ${ }^{3}$ University Hospitals Leuven, Dept of Otorhinolaryngology, Head \& Neck Surgery, Leuven, Belgium. ${ }^{4}$ The Royal National Throat Nose and Ear Hospital, London, UK. ${ }^{5}$ Meda, Corporate Clinical Affairs, Bad Homburg, Germany. ${ }^{6}$ Hospital Clinic IDIBAPS, CIBERES, Barcelona, Spain.}

Published: 26 June 2015

\section{doi:10.1186/2045-7022-5-S4-P38}

Cite this article as: Bachert et al:: A new intranasal therapy (MP29-02*) is more effective than current firstline therapy regardless of season,

symptom or severity.. Clinical and Translational Allergy 2015 5(Suppl 4):P38. 